\title{
Article \\ Three-Dimensional Ultrasonic Imaging and Acoustic Emission Monitoring of Hydraulic Fractures in Tight Sandstone
}

\author{
Wei Zhu ${ }^{1}{ }^{1}$, Shangxu Wang ${ }^{1}$, Xu Chang ${ }^{2, *}$, Hongyu Zhai ${ }^{3}$ and Hezhen $W^{3}$ \\ 1 State Key Laboratory of Petroleum Resources and Prospecting, China University of Petroleum (Beijing), \\ Beijing 102249, China; zhuw@cup.edu.cn (W.Z.); wangsx@cup.edu.cn (S.W.) \\ 2 Institute of Geology and Geophysics, Chinese Academy of Sciences, Beijing 100029, China \\ 3 Institute of Geophysics, China Earthquake Administration, Beijing 100081, China; \\ zhaihy@cea-igp.ac.cn (H.Z.); wuhezhen@cea-igp.ac.cn (H.W.) \\ * Correspondence: changxu@mail.iggcas.ac.cn
}

check for updates

Citation: Zhu, W.; Wang, S.; Chang, X.; Zhai, H.; Wu, H.

Three-Dimensional Ultrasonic Imaging and Acoustic Emission Monitoring of Hydraulic Fractures in Tight Sandstone. Appl. Sci. 2021, 11, 9352. https://doi.org/10.3390/ app11199352

Academic Editors: Gerd Manthei and Giuseppe Lacidogna

Received: 26 July 2021

Accepted: 2 October 2021

Published: 8 October 2021

Publisher's Note: MDPI stays neutral with regard to jurisdictional claims in published maps and institutional affiliations.

Copyright: (C) 2021 by the authors Licensee MDPI, Basel, Switzerland. This article is an open access article distributed under the terms and conditions of the Creative Commons Attribution (CC BY) license (https:// creativecommons.org/licenses/by/ $4.0 /)$
Featured Application: This work is highly significant for hydraulic fracturing construction and interpretation in the field.

Abstract: Hydraulic fracturing is an important means for the development of tight oil and gas reservoirs. Laboratory rock mechanics experiments can be used to better understand the mechanism of hydraulic fracture. Therefore, in this study we carried out hydraulic fracturing experiments on Triassic Yanchang Formation tight sandstone from the Ordos Basin, China. Sparse tomography was used to obtain ultrasonic velocity images of the sample during hydraulic fracturing. Then, combining the changes in rock mechanics parameters, acoustic emission activities, and their spatial position, we analyzed the hydraulic fracturing process of tight sandstone under high differential stress in detail. The experimental results illuminate the fracture evolution processes of hydraulic fracturing. The competition between stress-induced dilatancy and fluid flow was observed during water injection. Moreover, the results prove that the "seismic pump" mode occurs in the dry region, while the "dilation hardening" and "seismic pump" modes occur simultaneously in the partially saturated region; that is to say, the hydraulic conditions dominate the failure mode of the rock.

Keywords: hydraulic fracturing; acoustic emission; sparse tomography; tight sandstone

\section{Introduction}

Tight oil and gas reservoirs are an important part of mineral energy in China. However, their low permeability $(<0.5 \mathrm{mD})$ makes it difficult to exploit them. Therefore, it is necessary to improve the reservoir and enhance oil recovery by hydraulic fracturing. The process of hydraulic fracturing involves not only solid deformation caused by fluid pressure before fracture, but also fracture initiation and propagation during fracture, as well as fluid flow and seepage after fracture [1]. If these key mechanical problems can be grasped and understood, the process of fracture development can be predicted and evaluated, thus providing important references for optimizing hydraulic fracturing plans and improving recovery efficiency. By conducting hydraulic fracturing experiments in the laboratory, the influence of environmental factors can be reduced, and the dynamic development process and distribution ranges of fractures can be obtained using multiple physical means, such as acoustic emission monitoring, ultrasonic velocity, and X-ray tomography [2-5].

Acoustic emission events (AEs) originate from crack rupture induced by mechanical, thermal, or hydraulic factors [6-9]. By investigating the AE characteristics (including count, amplitude, and location), we can obtain the failure law of hydraulic fracturing indirectly [10]. AE count is always used to quantify the AE activity [8], which represents the occurrence of the microcrack during the loading tests. AE peak amplitudes reflect the magnitude of fracture. The slope of the frequency magnitude distribution, $b$-value, is 
considered to represent the states of fracture $[8,11]$. Numerous laboratory studies provide that the b-value always decreases when the stress increases [12-16], which makes it possible to predict failure using precursory changes in the b-value. Except for the AE amplitude, the characteristics of the $\mathrm{AE}$ waveform can be used to identify the fracture mode by moment tensor inversion [17-21]. Since the $\mathrm{AE}$ is associated with the fracture of the rocks, analyzing the spatiotemporal distribution of $\mathrm{AE}$ can capture the initiation and propagation of hydraulic fractures. In fact, AE location has been widely used to study the process of hydraulic fracturing in the laboratory [22-29]. In addition, AE source localization could be used to determine the location of the fracture surface [22].

Although AE can explain the fracture process very well, it cannot fully reveal the fracture evolution of hydraulic fracturing, especially the mechanism of interaction between hydraulic fracturing and fluid flow. Therefore, to more fully understand the dynamic process of hydraulic fracturing, it is necessary to determine the distribution of fluid and flow process within the rock. As fluid could cause changes in the ultrasonic velocity of the rock [30-35], the fluid distribution in the rock could be known if the 2D/3D rock velocity images can be obtained. For example, ref. [36] obtained the rock velocity structure using ultrasonic tomography (UT) and analyzed the process of fluid penetration in dry Oshima granite. Therefore, as a traditional means of studying rock deformation and fracture $[7,37-41]$, ultrasonic tomography can also be used to study the hydraulic fracturing of rocks.

Joint analysis of AE and UT can help to understand the micromechanical response of rock to the stress field and fluid penetration effect [6]. AE and UT have brought us many interesting findings about the process of hydraulic fracturing. For example, a positive feedback mode between hydraulic fracturing and fluid flow was found in [42]. The investigation of [43] proved that the injected high-pressure oil would cause AE activities when the rock was at low-stress levels. A dynamic coupling process of fluid flow and rock deformation can also be found in $[6,44]$.

Apart from AE and UT, X-ray computerized tomography $(\mu \mathrm{CT})$ is often used to depict and analyze the fractures induced by hydraulic fracturing [2,45-49]. Due to the detailed description of fractures by $\mu \mathrm{CT}$, this technology can also be applied to prove the relationship between fracture and AE focal mechanism [21], AE location [44,46-48,50-52], or ultrasonic imaging $[44,49]$.

Because hydraulic fracturing is very complex, research methods using a single means cannot fully explain this process, so research methods combining multiple means are becoming a trend. For example, ref. [53] proved that the waterfront position is closely related to the tip of the $\mathrm{AE}$ cloud by monitoring the temporal and spatial variation of acoustic emission, velocity, and fluid injection volume of porous sandstone during hydraulic fracturing. In this paper, a laboratory hydraulic fracturing experiment was carried out on tight sandstone. Combining rock mechanic parameters, hydraulic fracture CT scan images, acoustic emission density images, and 3D ultrasonic velocity images, we analyzed the fracture mode and fracture development process of tight sandstone during hydraulic fracturing. The experimental results in this paper are of great significance for the understanding of the fracture mechanism of hydraulic fracturing.

\section{Methodology}

2.1. Acoustic Emission Location

The arrival time of the acoustic emission signal can be expressed as:

$$
t=t^{(\mathrm{s})}+f\left(x^{(\mathrm{s})}, y^{(\mathrm{s})}, z^{(\mathrm{s})}, \mathbf{s}\right)
$$

where, $t^{(\mathrm{s})}$ and $\left(x^{(\mathrm{s})}, y^{(\mathrm{s})}, z^{(\mathrm{s})}\right)$ represent the original time and location of acoustic emission, respectively. The function $f$ represents the propagation time of $\mathrm{AE}$, which is related to 
the source position and the slowness $\mathbf{s}$ (reciprocal of the velocity $v$ ). For an isotropic homogeneous medium with velocity $v$, it can be written as:

$$
f=\sqrt{\left(x_{i}^{(r)}-x^{(\mathrm{s})}\right)^{2}+\left(y_{i}^{(r)}-y^{(\mathrm{s})}\right)^{2}+\left(z_{i}^{(r)}-z^{(\mathrm{s})}\right)^{2}} / v
$$

where $\left(x_{i}^{(r)}, y_{i}^{(r)}, z_{i}^{(r)}\right)$ is the position of the $i$ th receiver. Substitute Equation (2) into Equation (1) and simplify it; then, the following expression can be obtained:

$$
g_{i 1} m_{1}+g_{i 2} m_{2}+g_{i 3} m_{3}+g_{i 4} m_{4}+g_{i 5} m_{5}+g_{i 6} m_{6}=d_{i}
$$

where

$$
\begin{aligned}
& g_{i 1}=1, g_{i 2}=-2 x_{i}, g_{i 3}=-2 y_{i}, g_{i 4}=-2 z_{i}, g_{i 5}=2 t_{i}, g_{i 6}=-t_{i}^{2} \\
& m_{1}=\left(x^{(s)}\right)^{2}+\left(y^{(s)}\right)^{2}+\left(z^{(s)}\right)^{2}-\left(v t^{(s)}\right)^{2} \\
& m_{2}=x^{(s)}, m_{3}=y^{(s)}, m_{4}=z^{(s)}, m_{5}=t^{(s)} v^{2}, m_{6}=v^{2}, d_{i}=-\left(x_{i}^{2}+y_{i}^{2}+z_{i}^{2}\right)
\end{aligned}
$$

The matrix form of Formula (3) can be expressed as:

$$
G m=d
$$

Set the solution of the linear equations as $\widetilde{m}$, then the source parameters and velocity can be expressed as:

$$
x_{s}=\widetilde{m}_{2}, y_{s}=\widetilde{m}_{3}, z_{s}=\widetilde{m}_{4}, t_{s}=\widetilde{m}_{5} / \widetilde{m}_{6}, v=\sqrt{\widetilde{m}_{6}}
$$

\subsection{Sparse Tomography}

The inversion problem of rock ultrasonic velocity tomography can be expressed as the minimization problem:

$$
\tilde{\mathbf{s}}=\underset{\mathbf{s}}{\operatorname{argmin}} \frac{1}{2}\left\|\mathbf{A s}-\mathbf{T}^{\mathrm{obs}}\right\|_{2}^{2}
$$

where $\mathbf{A}$ is the sensitive kernel matrix, representing the length of rays in the spatial grid; $\mathbf{s}$ is the slowness in each grid; and $\mathbf{T}^{\mathrm{obs}}$ is the observed travel time. Inversion problems such as (7) are often ill-conditioned due to limited observation angles and noise interference, which makes them very difficult to solve. To obtain a stable and unique solution, a regularization term $\Omega(\mathbf{s})$ could be added to the right side of Equation $(7)[54,55]$. The most classical regularization method is Tikhonov regularization [56], whose regularization term is the 2-norm of the model. However, its solution is too smooth. If we take the regularization term as the 0-norm of the model or its approximation (such as total variation, TV), we can obtain a sparse solution. Then, the minimization problem (7) becomes:

$$
\underset{\mathbf{s}}{\operatorname{argmin}} \frac{1}{2}\left\|\mathbf{A s}-\mathbf{T}^{\mathrm{obs}}\right\|+\lambda \int\|\nabla \mathbf{s}\|_{1}^{1} d V
$$

where the second term is the TV regularization term and $\lambda$ is the regularization parameter, which balances the fits of the data and the weights of the regularization term. Since this method adopts the sparse regularization term, we call this method sparse tomography. The work in [57] proved that this method can be used to reconstruct hydraulic fracturing fractures, so we used this method to obtain the 3D ultrasonic velocity imaging in the sample.

\section{Experiment}

\subsection{Specimen Details}

The test sample (Figure 1a) is a tight sandstone cored from an outcrop of the Triassic Yanchang Formation in the Ordos Basin, China. It had a diameter of $50 \mathrm{~mm}$ and a length of $125 \mathrm{~mm}$. The density and the porosity of the sample were about $2.39 \mathrm{~g} / \mathrm{cm}^{3}$ and $5.7 \%$, 
respectively. The strength of the dry sample was about $270 \mathrm{Mpa}$ under confining pressure of $35 \mathrm{Mpa}$. Moreover, a borehole with a diameter of $6 \mathrm{~mm}$ and a depth of $80 \mathrm{~mm}$ was drilled into the sample.

(a)

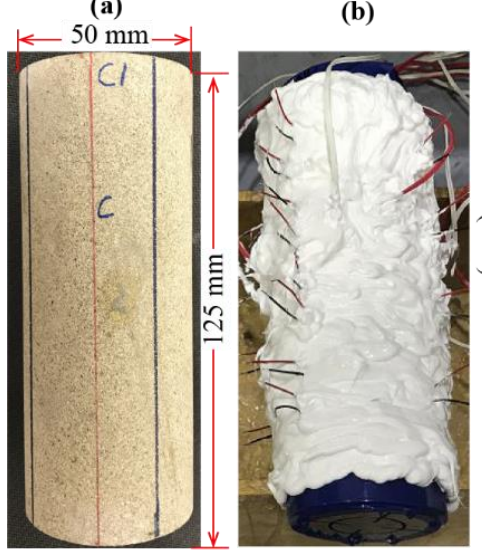

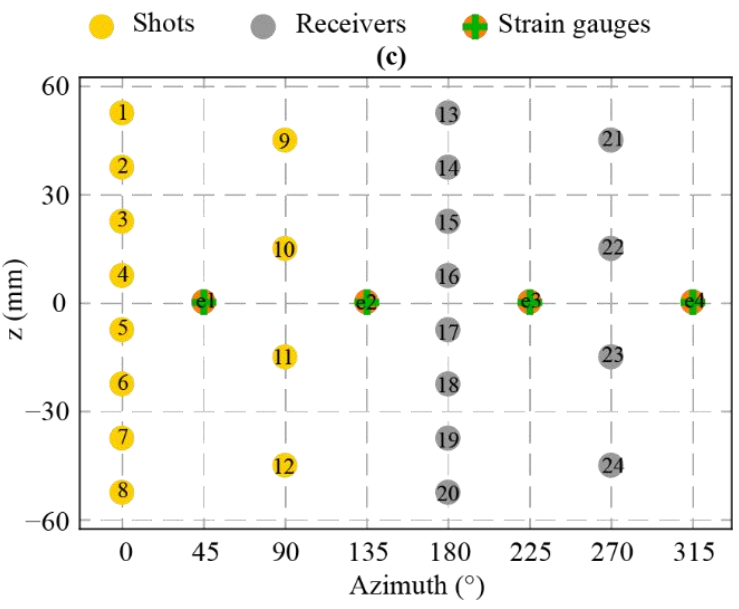

Figure 1. (a) Rock sample; (b) the sample coated with silicone sealant; (c) cylindrical expansion view of the installation position of transducers and strain gauges.

To monitor $\mathrm{AE}$ and ultrasonic velocity during the experiment, 24 piezo electrical transducers (PZTs, of which the resonant frequency was $2 \mathrm{MHz}$ ) with a diameter of $5 \mathrm{~mm}$ were arranged on the rock surface (Figure 1c). Four pairs of mutually orthogonal strain gauges e1 e4 were arranged around the sample to monitor the change in axial and circumscribed strains. To prevent the confining oil from leaking into the sample, a silicone sealant with a thickness of $5 \sim 6 \mathrm{~mm}$ was coated on the sample and the two end pieces (Figure 1b).

\subsection{Experimental Set-Up}

The experimental system consisted of the stress-loading system (Figure 2a, the maximum load was 2000 tons), the acoustic emission acquisition system (Figure 2b, the maximum sampling rate was $100 \mathrm{MHz}$, this experiment used $25 \mathrm{MHz}$ ), and the stress and strain monitoring system (Figure 2c, the resolution was 16 bit).

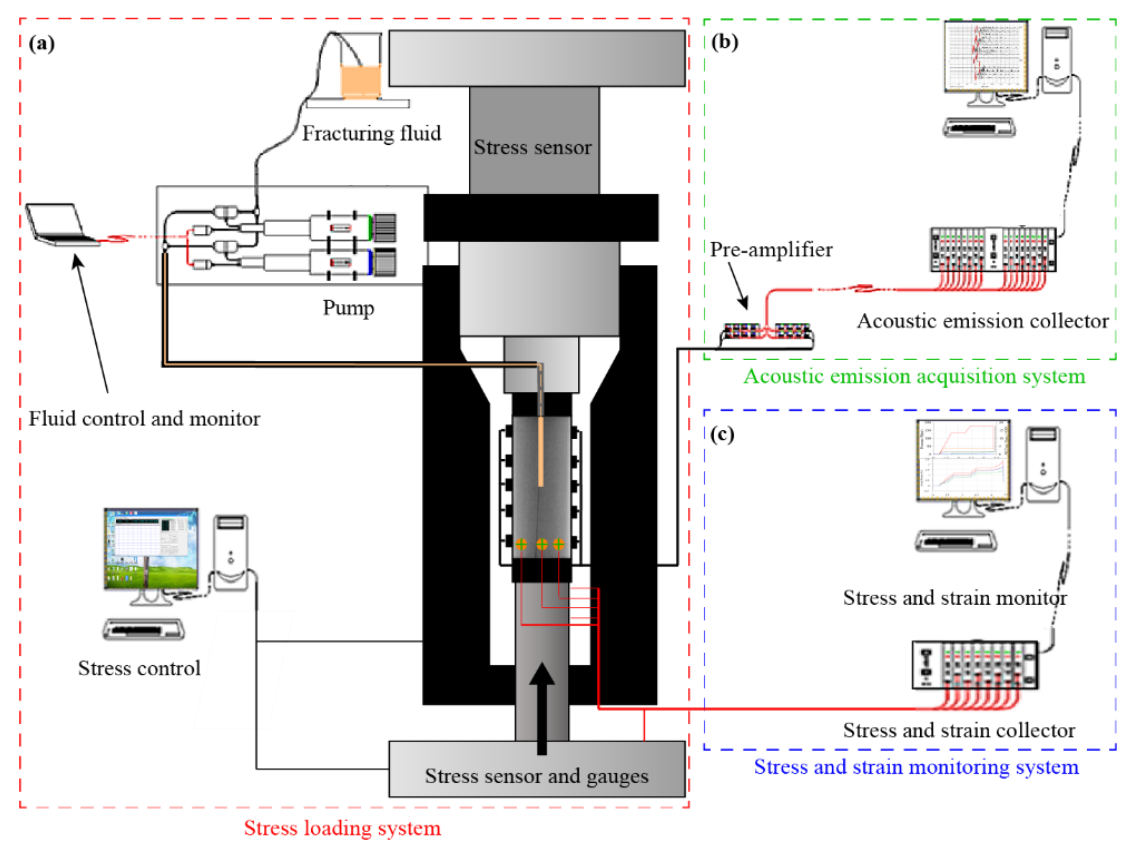

Figure 2. Schematic diagram of the experimental system (citing from [49]). 
As shown in Figure 3, the experiment lasted $7.5 \mathrm{~h}$ and could be roughly divided into five stages: hydrostatic loading stage (L0), water-saturation stage (L1), axial loading stage (L2), hydraulic fracturing stage (L3), and rock fracture stage (L4). In the L0 stage, the axial $\left(P_{\mathrm{a}}\right)$ and confining pressure $\left(P_{\mathrm{c}}\right)$ were simultaneously increased to $35 \mathrm{MPa}$ at a loading rate of $2 \mathrm{MPa} / \mathrm{min}$. At the L1 stage, we kept $P_{\mathrm{c}}$ at $35 \mathrm{MPa}$ and increased the axial pressure to $132 \mathrm{MPa}$ at a loading rate of $2 \mathrm{MPa} / \mathrm{min}$. Then, distilled water was injected into the borehole continually. About half an hour later, the water injection pressure $\left(P_{\text {in }}\right)$ reached 4.7 MPa, and the flow rate was stabilized at $0.001 \mathrm{~mL} / \mathrm{min}$. In the L2 stage, we kept $P_{\mathrm{c}}$ and $P_{\text {in }}$ constant and increased $P_{\mathrm{a}}$ to $176 \mathrm{MPa}(65 \%$ of the strength of dry rock under the same confining pressure). In the L3 stage, we kept $P_{\mathrm{a}}$ and $P_{\mathrm{c}}$ constant, and water was injected into the sample gradually. After about half an hour, the flow rate was stabilized at $0.02 \mathrm{~mL} / \mathrm{min}$, and after about $100 \mathrm{~min}$, the water pressure was increased to $16.25 \mathrm{MPa}$. In the L4 stage, the water injection pressure began to decline slowly, and about 13 min later, the water injection pressure and axial pressure suddenly decreased rapidly, and the rock ruptured. Finally, axial loading stopped automatically.

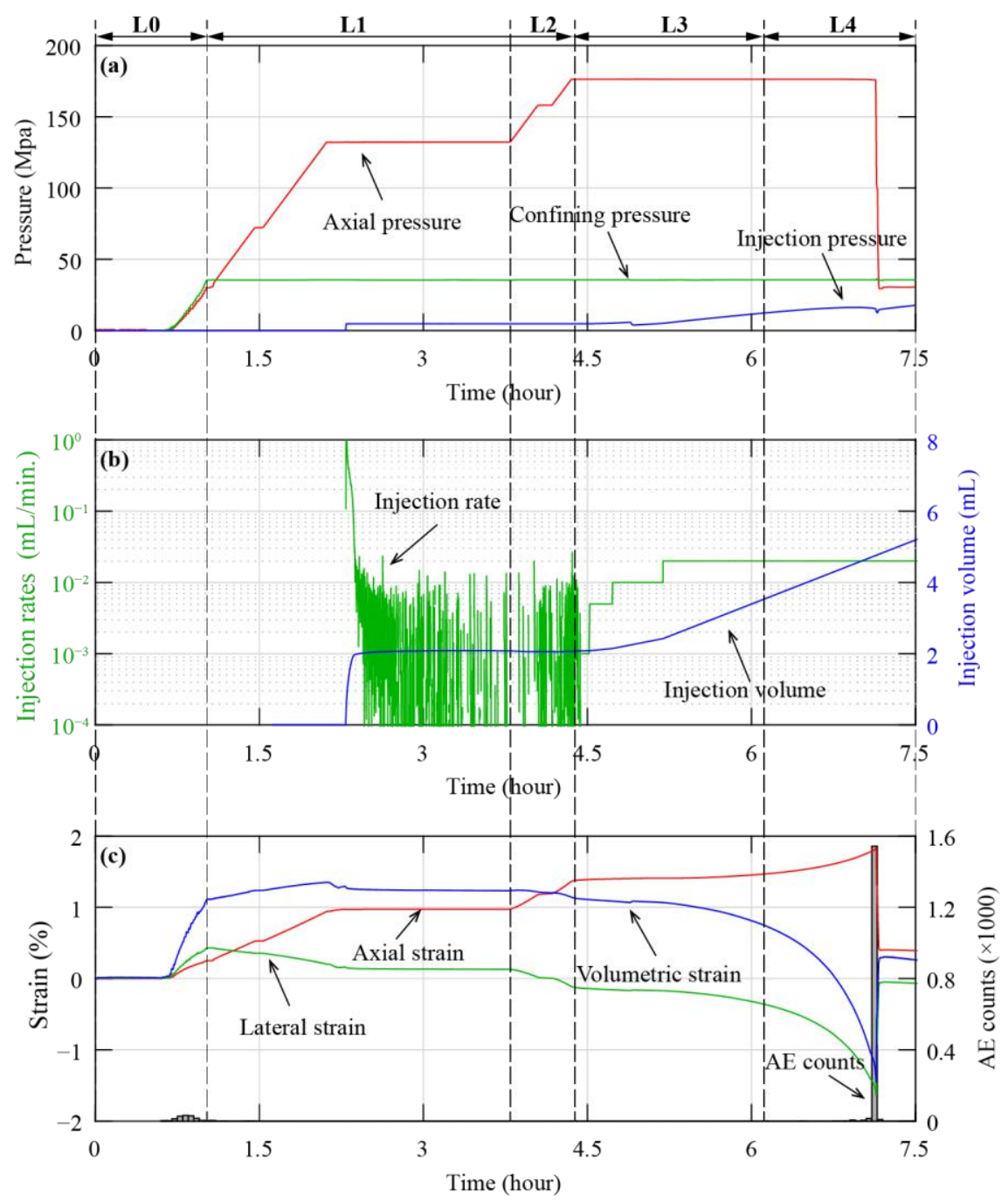

Figure 3. The loading history of the sample. The temporal variations of (a) stress; (b) water injection rate and volume; (c) strain and acoustic emission count. The experiment can be roughly divided into four stages: hydrostatic loading stage (L0), water-saturation stage (L1), axial loading stage (L2), hydraulic fracturing stage (L3), and rock fracture stage (L4). The black dotted line marks the demarcation points for each stage. 


\subsection{AE Monitoring}

After acoustic emission signals arrived at 24 PZTs, they were firstly pre-amplified by $45 \mathrm{~dB}$ and then digitized at a sampling rate of $25 \mathrm{MHz}$. To count the AE events, AE signals from two selected sensors were amplified by $20 \mathrm{~dB}$ and then fed to peak detectors with a dynamic range of $100 \mathrm{~dB}$. There were only $1720 \mathrm{AE}$ event waveforms recorded in our test. The P-wave's first motions of AE were selected using the automatic method based on the Akaike information criterion (AIC) [58]. Then, manual checks were performed to prevent the wrong picks. To obtain better location precision, only the source locations of AE events with more than eight $\mathrm{P}$-wave arrival times were determined. The location errors for most AEs were better than $2 \mathrm{~mm}$. To highlight the spatial distribution of AE events, AE density at each voxel was calculated as the reciprocal of the sum of squared distances from each AE location.

We determined the magnitude $M$ of $\mathrm{AE}$ events following [59]:

$$
M=\log \left(A_{\max } / A_{0}\right)+M_{0}
$$

where $A_{\max }$ is the maximum amplitude of the $\mathrm{AE}$ signal, $A_{0}$ is the threshold for detection, and $M_{0}=-11$ is a calibration parameter to roughly estimate the absolute AE magnitude. Based on the AE data recorded, the maximum likelihood method was used to estimate the frequency magnitude distribution. The temporal changes in b-values were calculated for a running window of a constant $\mathrm{AE}$ number $n=500$. According to the overall $\mathrm{AE}$ activity in a specific time window, we calculated the b-values for the $n(\geq 50)$ closest AEs to each voxel within a maximum radius of $R_{\max }=25 \mathrm{~mm}$. The b-map is beneficial for explaining stress redistribution during the fracture.

\subsection{UT Imaging}

Twelve PZTs (Num. 1 12 in Figure 1c) were selected as sources to emit the ultrasonic wave. The waveform acquisition system for the UT was the same as that for AE. Ultrasonic measurements were performed at a time interval of 2 min during water injections. To utilize the sparse tomography introduced above, the onset time was picked using the AIC method, and ray paths were obtained using the fast-marching method [60]. According to our previous research, the root-mean-square error of the inverse velocity is lower than $100 \mathrm{~m} / \mathrm{s}$.

\section{5. $\mu$ CT Imaging}

The internal structure of the sample was obtained using medical CT scanning equipment (Toshiba Aquilion ONE TSX 301A, Tokyo, Japan) before and after the experiment. The scanning voltage was $135 \mathrm{kV}$, slice thickness was $0.5 \mathrm{~mm}$, the sampling interval was $0.106 \mathrm{~mm}$, and the pixel grid was $512 \times 512$.

\section{Results}

\subsection{Mechanical Response}

The temporal variations in axial $\left(\varepsilon_{a}\right)$, lateral $\left(\varepsilon_{l}\right)$, and volumetric strain $(\theta)$ are shown in Figure 3c. In the L0 stage, the sample was compacted rapidly due to the isotropic stress. At the beginning of the L1 stage, the sample exhibited elastic deformation. With the increase in differential stress, the sample gradually deviated from elasticity (Figure 4). The deviation from elastic strain (dotted line in Figure 4) represents the inelastic increase in rock volume $\left(\Delta=\theta_{e}-\theta\right)$, which is called volumetric dilation. At the L3 and L4 stages, the water injection further promoted volumetric dilation (Figure $5 b$ ). 


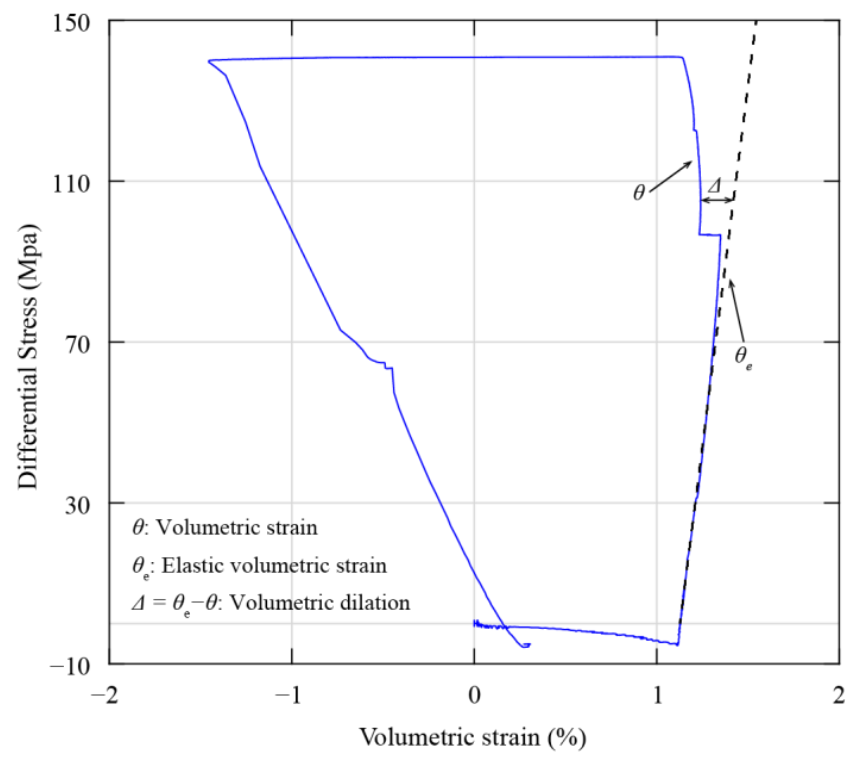

Figure 4. Volumetric strain varied with the differential stress.

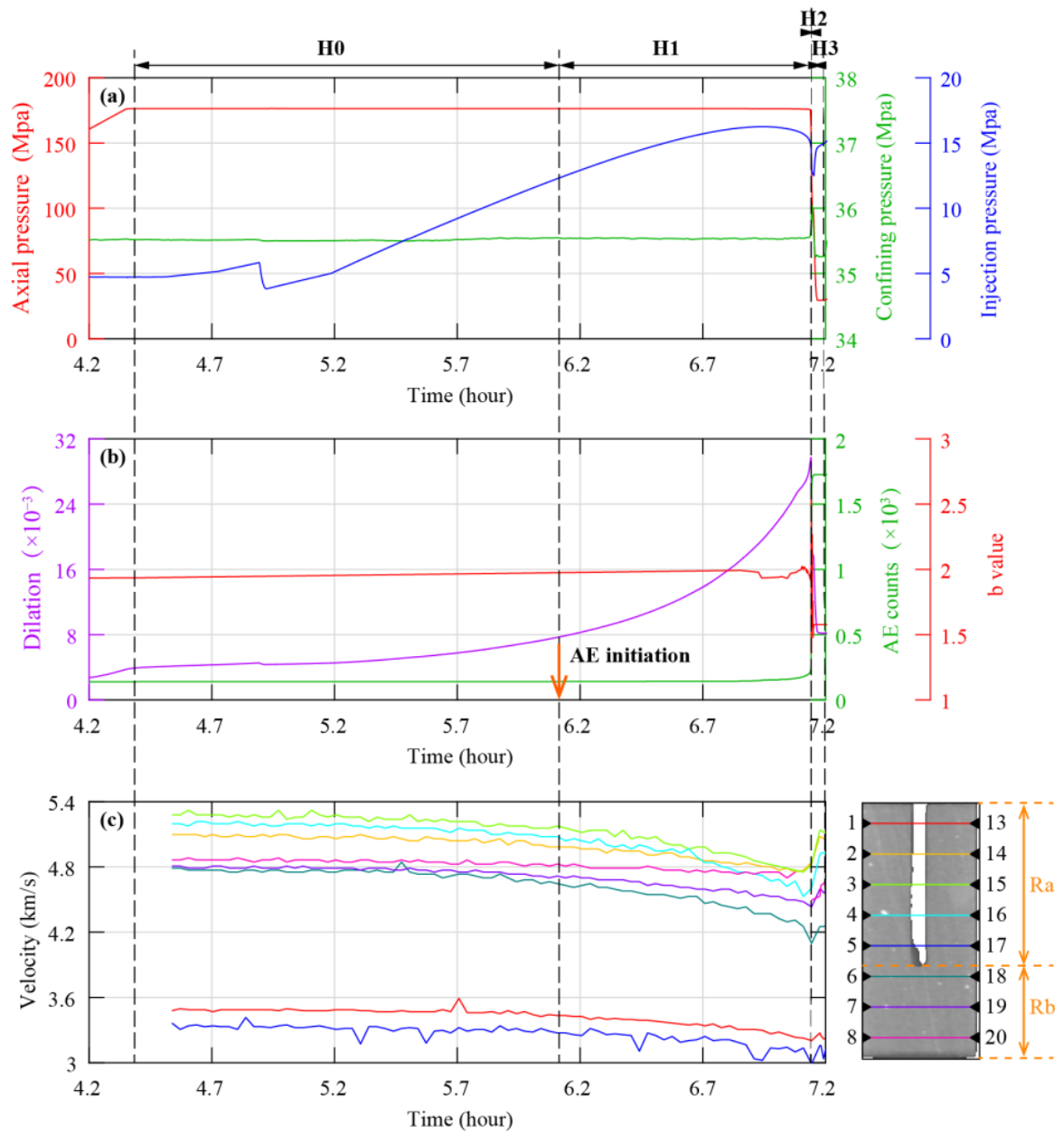

Figure 5. Close-up view of rock loading history (L3 and L4 stages in Figure 3): (a) pressure; (b) volumetric dilation, the cumulative AE number, and change in b-value; (c) change in ultrasonic velocities (different colors represent different paths). According to water injection pressure and the time distribution of acoustic emission, the experiment at this stage can be roughly divided into four phases: pore pressure increasing phase $(\mathrm{H} 0)$, pre-fracture phase $(\mathrm{H} 1)$, fracture nucleation phase $(\mathrm{H} 2)$, and post-fracture phase (H3). The black dotted lines represent the boundaries of the phases. 


\subsection{Evolution of P-Wave Velocity}

Only the P-wave velocities at the L3 and L4 stages were measured. Figure $5 \mathrm{c}$ shows the velocities measured along eight horizontal ray paths. For the convenience of description, $\mathrm{Ra}$ and $\mathrm{Rb}$ refer to the regions above and below the bottom of the borehole, respectively. The unequal velocities were observed along the ray paths located in Ra. In contrast, almost equal velocities were found along the ray path (S6-R18, S7-R19, S8-R20) located in Rb at the early period of the water injection. Additionally, we found that the former (excepting S1-R13 and S5-R17) was higher than the latter. Since the velocities were dependent on the microcrack distribution and water saturation, it can be inferred that Ra has a more heterogeneous microcrack distribution and a higher water saturation than $\mathrm{Rb}$. Before $\mathrm{AE}$ initiation, all the P-wave velocities along these ray paths decreased slightly with increasing injection pressure. After that, no significant decrease was observed in the P-wave velocities along ray path S8-R20, but the other velocities decreased continuously. The most significant decreases in the velocities were observed along ray paths S3-R15, S4-R16, S6-R18, and S7-R19. By comparing with the spatial distribution of AE, we found that these ray paths corresponded to the region where $\mathrm{AE}$ activities were clustered. After rock failure, all the velocities dramatically declined, but they increased again after a few minutes. These increases indicated that the rupture-induced decrease had been restrained by the entry of the water.

\subsection{Hydraulic Fracture Morphology}

Figure 6 shows the 3D borehole surface and hydraulic fracture surface extracted from the 3D CT scan images for the intact and fractured tight sandstone, respectively. Threedimensional fracture morphology presents that the hydraulic fracture has a rough curved surface, which is centered on the bottom of the borehole and propagates to both sides at an angle. Figures 7 and 8 show slice planes orthogonal to the $x-, y$-, and $z$-axis for volumetric $\mathrm{CT}$ data. As can be seen from these figures, the $\mathrm{CT}$ values in the fracture zone were very low, which indicated that the densities in these zones were very low. The dip angle differences between the upper and lower wing of the final fracture indicated that Ra and $\mathrm{Rb}$ had different fracture behaviors.

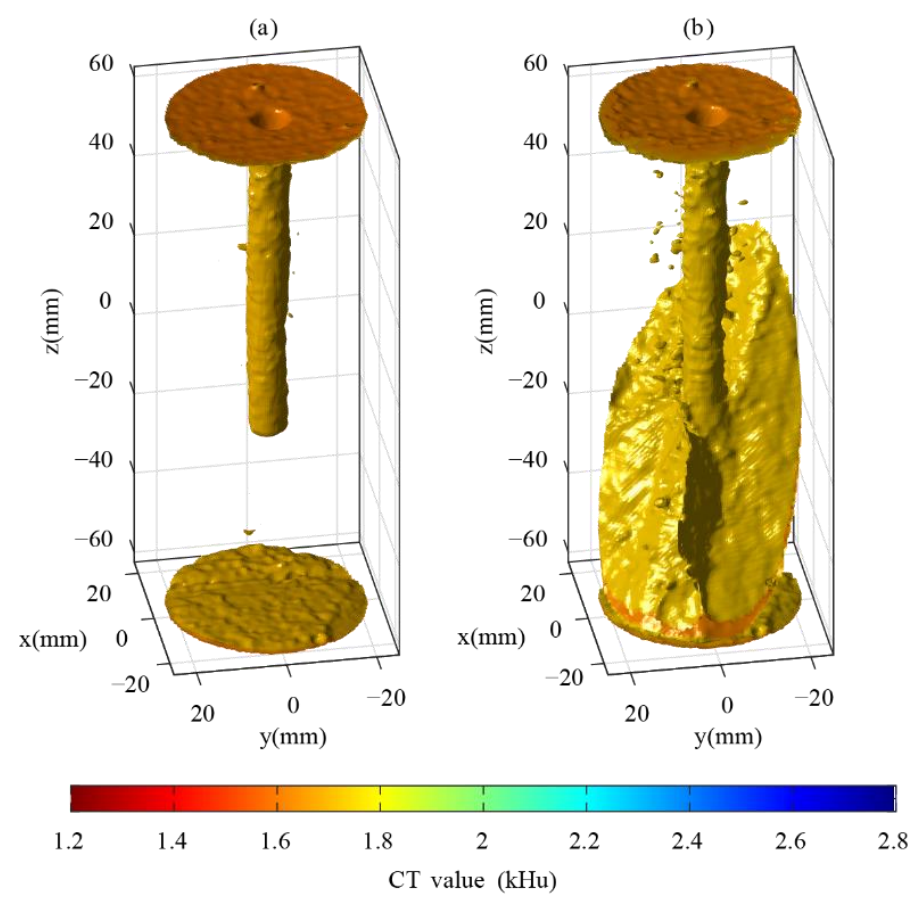

Figure 6. Three-dimensional borehole surface and hydraulic fracture surface extracted from the 3D CT scan images for the (a) intact and (b) fractured tight sandstone. 
(a) Slices normal to $\mathrm{z}$ direction

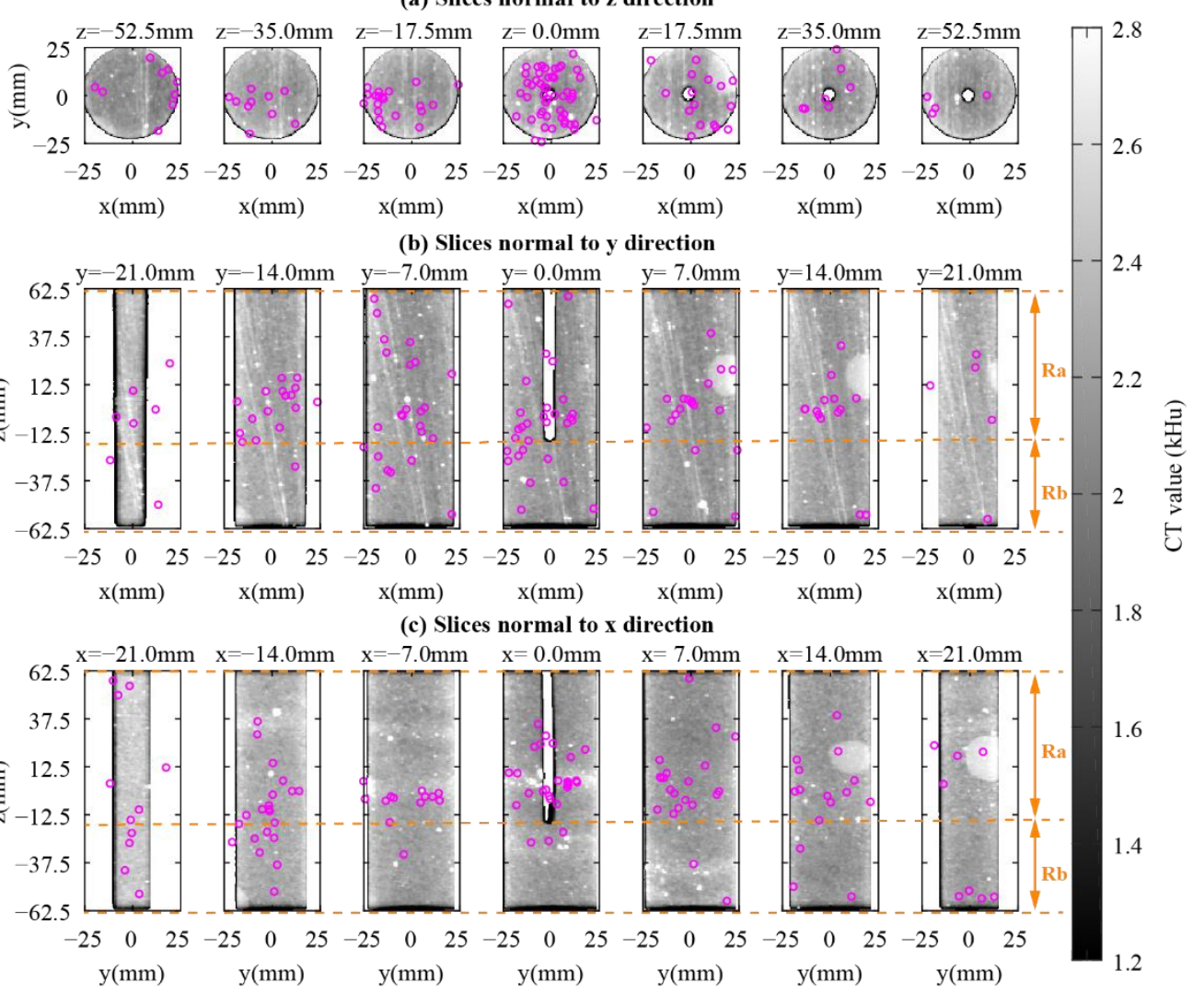

Figure 7. Comparison between the location of acoustic emission events (magenta circle) in stage L0 and CT scan images of rocks before the experiment. The orange dotted line represents the boundary between region $\mathrm{Ra}$ and $\mathrm{Rb}$.

\subsection{Acoustic Emission}

As shown in Figure 3c, two peaks of AE activity were observed in the L0 and L4 stages, respectively. The first peak was initiated at a low-stress level. Compared with the $\mathrm{X}$-ray CT scan images of rock before the experiment (Figure 7), the locations of these acoustic emission events were randomly distributed inside the sample. However, the increasing volumetric strain indicated that the rock was undergoing more volume compaction than solid elasticity. This behavior is attributed to the closing of preexisting cracks [61]. Hence, it can be considered that the first peak of the AE activity in this stage was mainly caused by the closure of natural microcracks. Under high differential stress, the second AE peak was initiated when the injection pressure approached $75 \%$ of its peak. From Figure 8 , we can see that the second $\mathrm{AE}$ activity was clustered around the fracture surface. Additionally, more clusters can be observed at $\mathrm{Ra}$, but the fewer clusters at $\mathrm{Rb}$ have a narrower offset range along the fracture surface. 
(a) Slices normal to $\mathrm{z}$ direction

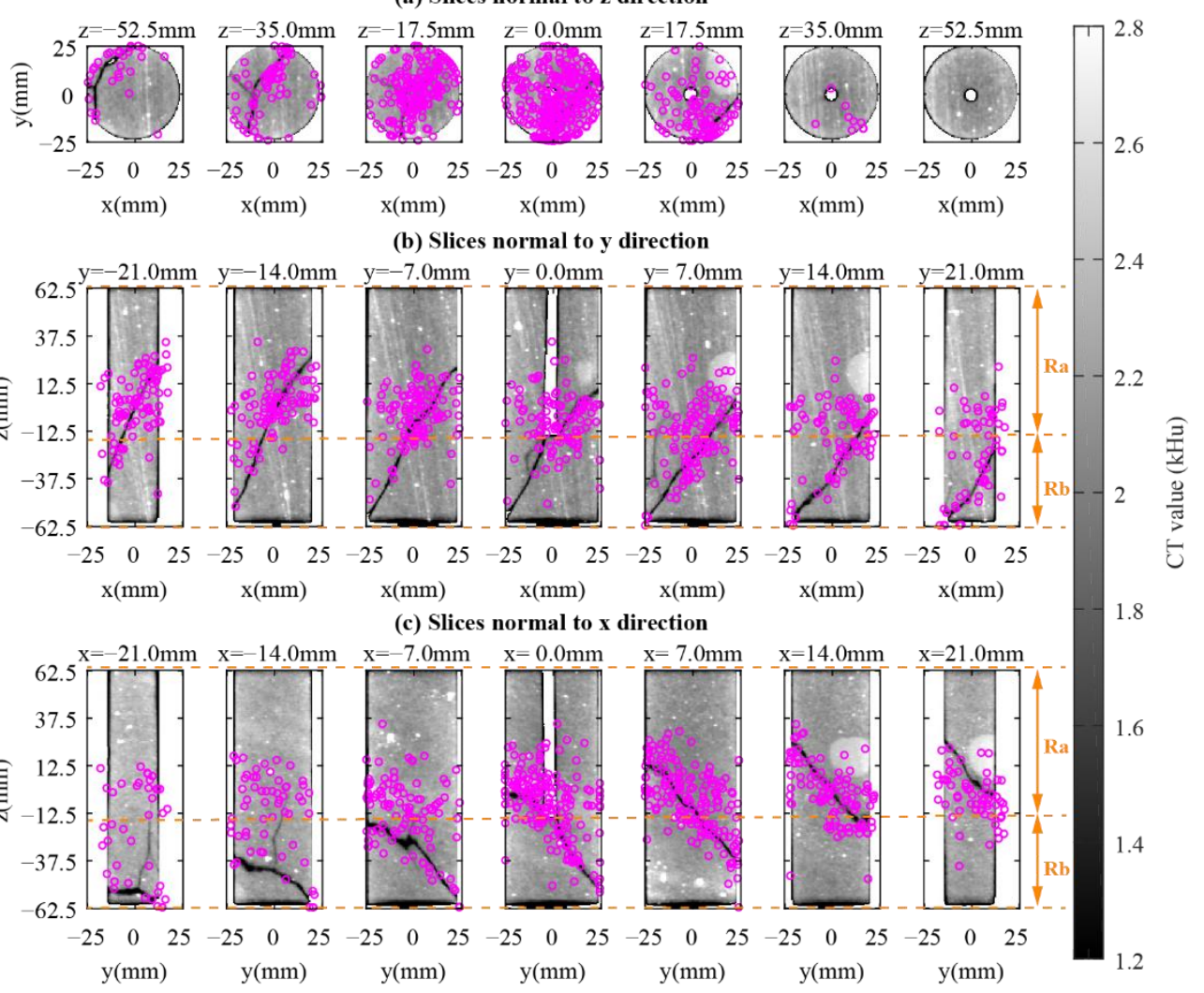

Figure 8. Comparison between the location of acoustic emission events (magenta circle) in the $\mathrm{H} 2$ phase and CT scan images after rock fracture. The orange dotted line represents the boundary between region $\mathrm{Ra}$ and $\mathrm{Rb}$.

\subsection{Fracture Process}

This study focused on the hydraulic fracturing process, so L3 and L4 stages are described in detail below. According to the evolution of the dilation, the AE counts, bvalue, and ultrasonic velocity, these two stages can be further divided into four phases: pore pressure increasing phase $(\mathrm{H} 0)$, pre-fracture phase $(\mathrm{H} 1)$, fracture nucleation phase $(\mathrm{H} 2)$, and post-fracture phase $(\mathrm{H} 3)$.

In phase $\mathrm{H} 0$, the axial and confining pressure remained constant, and the pore pressure gradually increased. The rock dilation gradually increased and the velocities slowly decreased (Figure $5 \mathrm{c}$ ). It is worth noting that the water injection pressure suddenly dropped by $2 \mathrm{Mpa}$ when it reached $5.84 \mathrm{MPa}$. However, no obvious acoustic emission events were recorded at this time, and no significant changes were observed in velocities. The evolution of axial pressure, confining pressure, and dilation demonstrated that all of these decreased slightly before the decrease in the injection pressure (Figure 9a,b). Three-dimensional UT images (Figure 9d) show that an obvious low-velocity zone was below the borehole (shown by the white dotted line box) at the initial time. This indicates that there may have been defects or microcracks below the borehole. Nevertheless, with the increasing pore pressure, the velocities in this area increased at Time B but dropped again at Time C. 

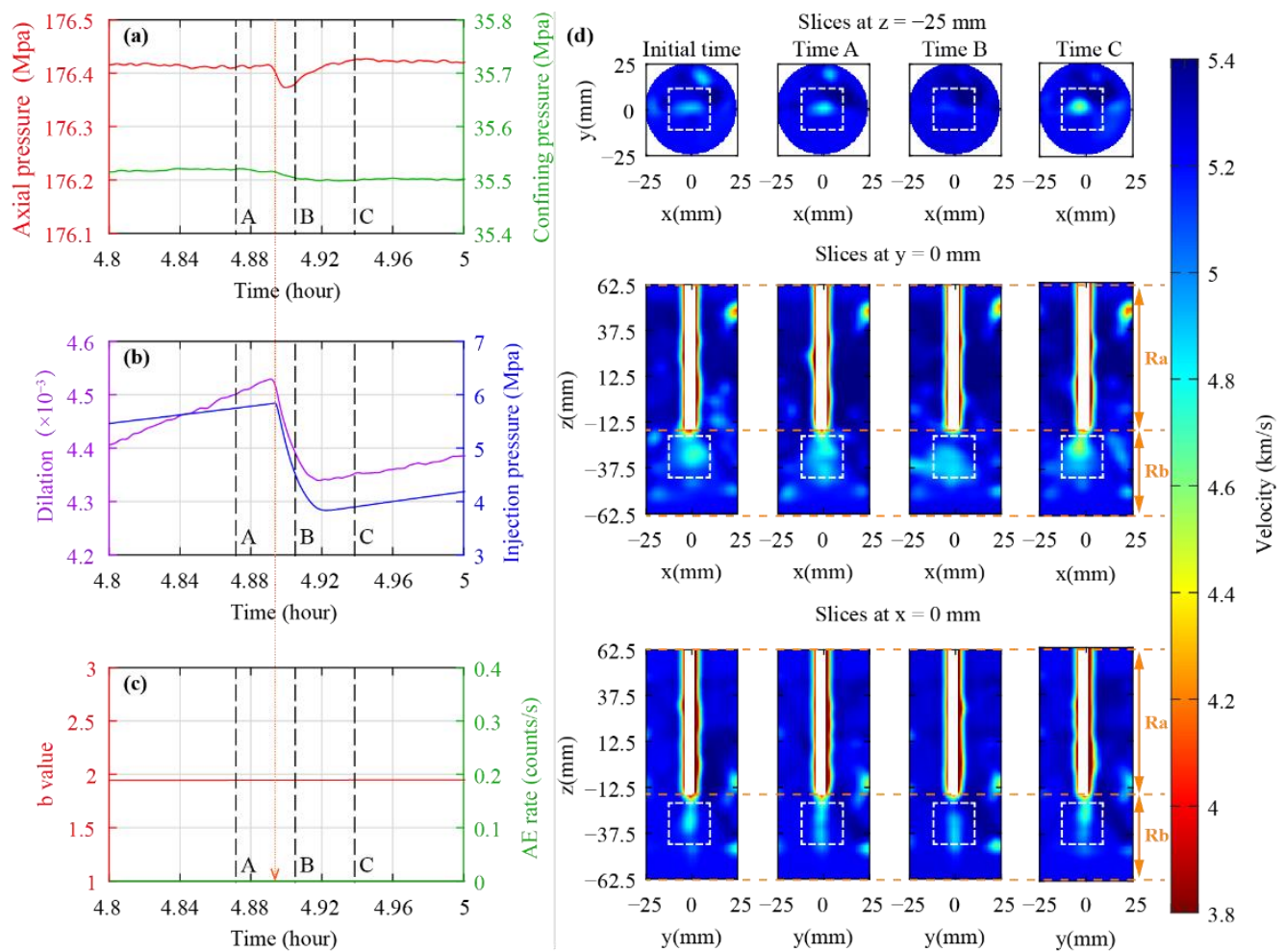

Figure 9. Mechanical response and velocity images of rock in $\mathrm{H} 0$ phase: (a) axial (red line) and confining pressure (green line); (b) dilation (purple line) and water injection pressure (blue line); (c) b-value (red line) and AE rate (green line); (d) slices of the 3D ultrasonic velocity images at different times (the initial time refers to the time when $\mathrm{H} 0$ starts, and the times $\mathrm{A}-\mathrm{C}$ correspond to the times marked by black dotted lines in the left subfigure). The orange dotted line in the left picture marks the moment when pore pressure starts to drop. The orange dotted line in the subfigure (d) represents the boundary between region $\mathrm{Ra}$ and $\mathrm{Rb}$. The white dotted line box represents the low-velocity zone below the borehole.

In phase $\mathrm{H} 1$, the second $\mathrm{AE}$ activity was initiated when the injection pressure reached $75 \%$ of its peak. Figure $5 \mathrm{c}$ shows that the sample underwent drastic variations in velocities in this phase. As shown in Figures 10 and 11, the AE events in this phase were clustered around the lower borehole. To better explain these variations, phase $\mathrm{H} 1$ has been further divided into two sub-phases: phase H1-1 and phase H1-2.

Phase H1-1 corresponds to the increasing injection pressure from $12.33 \mathrm{Mpa}$ to its peak 16.25 Mpa (Figure 10). The value of $b$ increased from 1.93 to 1.99 (Time D F), then dropped to 1.94 when $P_{\text {in }}$ approached its peak (Time G). In combination with the UT image AE locations in Figure 10d, it can be inferred that a localized deformation had occurred at the bottom of the borehole. The increasing AE activity and dilation and decreasing velocity demonstrated that intensive microcracks were in progress. The most striking result to emerge from the UT images was that the velocity drop was restrained to some extent by the entry of water at the region marked by the dashed white box in Figure 10d. 

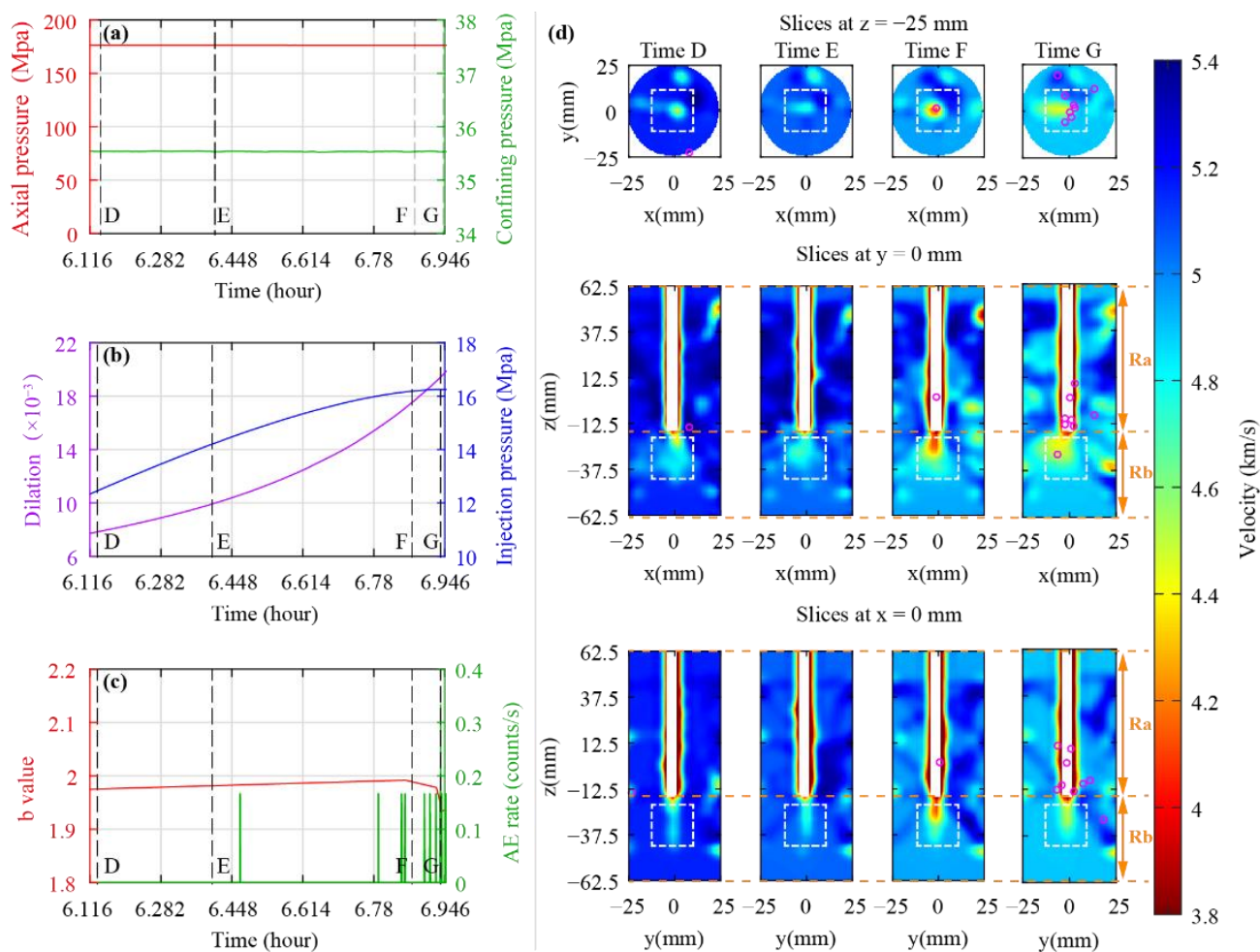

Figure 10. Mechanical response and velocity images of rock before water injection pressure reached peak value in $\mathrm{H} 1$ phase: (a) axial (red line) and confining pressure (green line); (b) dilation (purple line) and water injection pressure (blue line); (c) b-value (red line) and AE rate (green line); (d) slices of the 3D ultrasonic velocity images at different times (Times D G, respectively, correspond to the times marked by the black dotted lines in the left subfigures, and the magenta circles represent the positions of acoustic emission events occurring before the corresponding times). The orange dotted line in the subfigure (d) represents the boundary between region $\mathrm{Ra}$ and $\mathrm{Rb}$. The white dotted line box represents the low-velocity zone below the borehole.

In Phase H1-2, accelerated energy release caused the decline in the axial pressure and pore pressure (Figure 11). Injection-induced stress variation was reflected by the b-value (Times $\mathrm{H} \sim \mathrm{K})$. Increasing AE activity and dilation demonstrated that the generation of the microcracks was accelerating. From the UT images, we can see that the velocity in the Ra region was higher than that in $\mathrm{Rb}$. This can be explained as the higher water saturation in $\mathrm{Ra}$ than $\mathrm{Rb}$. Interestingly, although the velocity declined overall in the sample, the velocity drop in the Ra region was suppressed so much as its velocity increased obviously at Time K. Together with the mechanical response in this phase, we believe that "dilation hardening" started. Besides, the local low-velocity zone and its suppressed velocity drop could still be observed below the bottom of the borehole. 

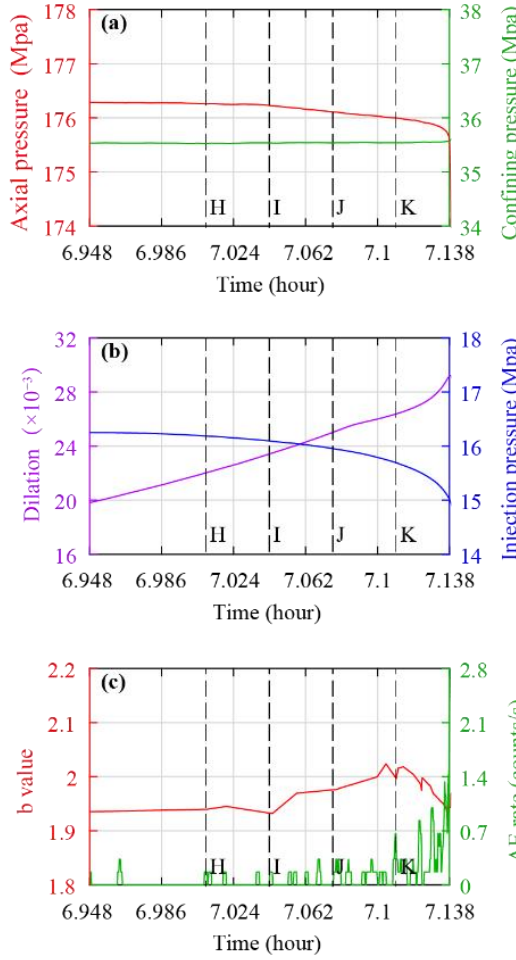

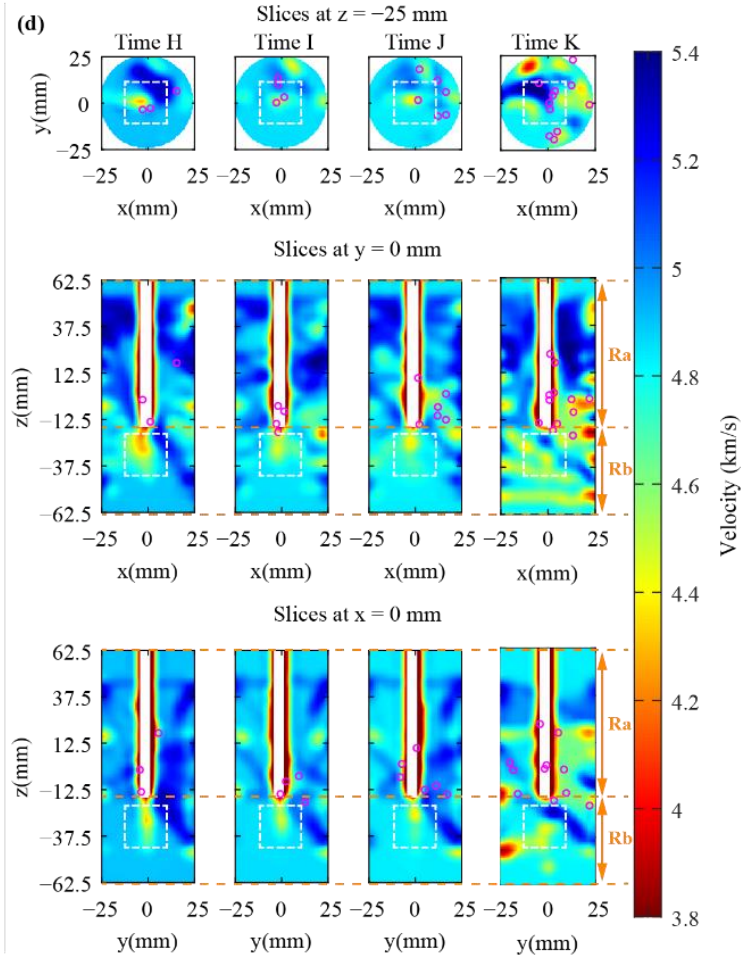

Figure 11. Mechanical response and velocity images of rock after water injection pressure reached peak value in $\mathrm{H} 1$ phase: (a) axial (red line) and confining pressure (green line); (b) dilation (purple line) and water injection pressure (blue line); (c) b-value (red line) and AE rate (green line); (d) slices of the 3D ultrasonic velocity images at different times (Times $\mathrm{H} \sim \mathrm{K}$, respectively, correspond to the times marked by the black dotted lines in the left subfigures, and the magenta circles represent the positions of acoustic emission events occurring before the corresponding times). The orange dotted line in the subfigure (d) represents the boundary between region $\mathrm{Ra}$ and $\mathrm{Rb}$. The white dotted line box represents the low-velocity zone below the borehole.

Phase $\mathrm{H} 2$ corresponds to the fracture nucleation, in which the water injection pressure dropped from 15.02 to $13.02 \mathrm{Mpa}$ rapidly, and the axial pressure dropped from 175.6 to 129.4 Mpa, but the confining pressure rose from 35.57 to $36.05 \mathrm{Mpa}$ (Figure 12). The AE rates reached their peak before the maximum stress drop. Acoustic emission first gathered near the upper wing of the final shear fracture (Times $L$ and $M$ ) and then nucleated in the $\mathrm{Rb}$ region (Times $\mathrm{N}$ and $\mathrm{O}$ ). The $\mathrm{AE}$ density maps show that the intense AE activity not only congregated on the fracture surface but also gathered around the bottom of the borehole (Figure 12c). Additionally, some newly generated AEs were continuously observed to cluster around the lower part of the borehole after the initiation of the fracture nucleation. With the intense generation of the microcracks, an increasing amount of fluid penetrated the sample through these newly generated microcracks in $\mathrm{Ra}$, which reduced the rock strength in this region and further promoted microcracks. Conversely, the far distance of $\mathrm{Rb}$ from the injection source and the low permeability made it difficult for the water to diffuse into this region. Hence, it can be considered that Ra has a better local drainage condition than $\mathrm{Rb}[51,62,63]$. Surprisingly, the value of $\mathrm{b}$ increased to 2.56 and then decreased gradually to 1.36. From the spatio-temporal maps of the b-value (Figure 13), we can see that the higher $\mathrm{b}$-value was concentrated in the Ra region before the fracture propagated to the $\mathrm{Rb}$ region (Times L N), which demonstrated the better drainage condition in Ra. However, a higher b-value was observed to be concentrated at the tip of the fracture (Time O). Since the higher b-value corresponds to the lower stress, we can infer that the stress release had occurred at the corresponding region. Moreover, the regional low $\mathrm{b}$-value indicated that the water had moved into a fractured region at Time $\mathrm{O}$. All these variations in the $b$-value indicated that the "seismic pump" mode occurred. 

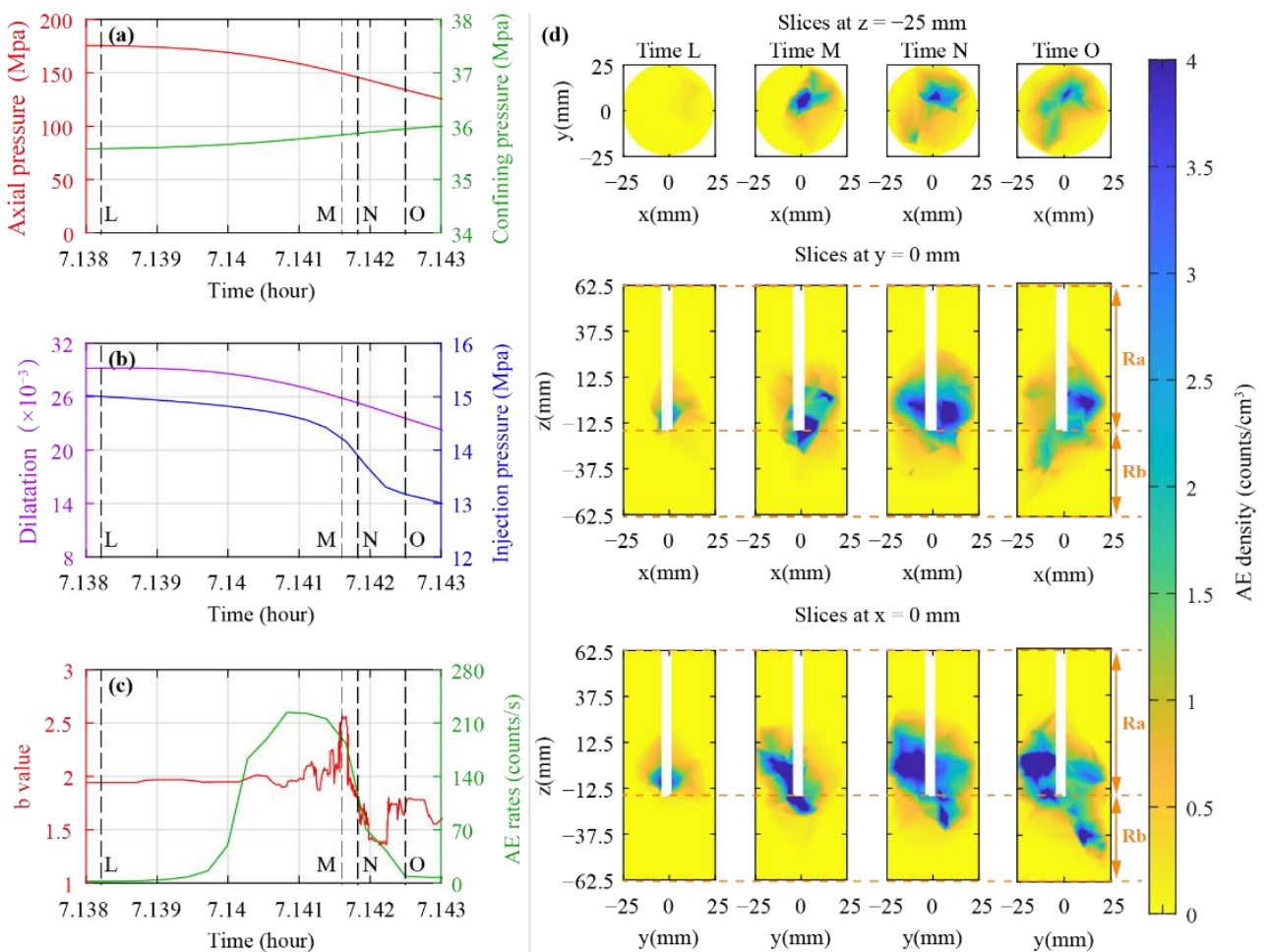

Figure 12. Mechanical response and acoustic emission density images of rock in $\mathrm{H} 2$ phase: (a) axial (red line) and confining pressure (green line); (b) dilation (purple line) and water injection pressure (blue line); (c) b-value (red line) and AE rate (green line); (d) slices of the 3D AE density images at different times (Times $\mathrm{L} \sim \mathrm{O}$ correspond to the time points marked by black dotted lines in the left subfigures). The orange dotted line in subfigures (d) represents the boundary between region $\mathrm{Ra}$ and $\mathrm{Rb}$.

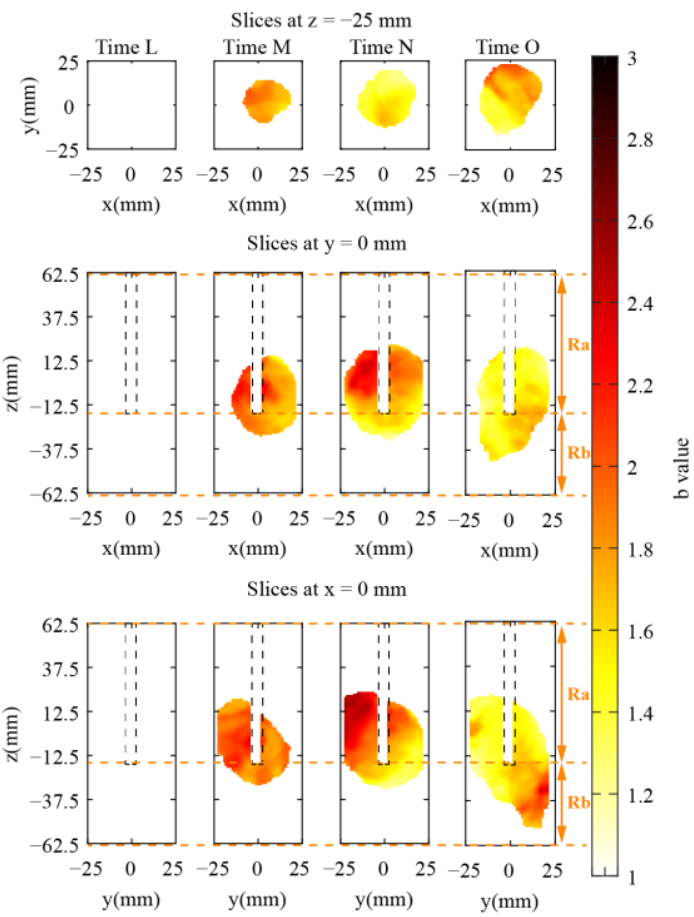

Figure 13. Spatio-temporal evolution of $b$-value in $\mathrm{H} 2$ phase. The orange dotted line represents the boundary between region $\mathrm{Ra}$ and $\mathrm{Rb}$. The dotted box represents the region with borehole. 
Phase H3 can be divided into two subphases: H3-1 and H3-2 (Figure 14). In phase H3$1, P_{\mathrm{a}}, P_{\mathrm{in}}$, and $\Delta$ decreased slightly before the confining pressure dropped to $35.6 \mathrm{Mpa}$. After the $\mathrm{AE}$ rate reached its second peak, the b-value increased from 1.36 to 2.27. Interestingly, a peak of b-value was observed before the third peak of the AE rate. As shown in the UT images in Figure 14d, an obvious low-velocity zone was below the borehole at Time P. In fact, this zone corresponds to the macroscopic shear fracture. In the phase H3-2, $P_{\mathrm{a}}, P_{\mathrm{c}}$, and $\Delta$ dropped to a constant, but $P_{\text {in }}$ increased to a constant. Meanwhile, AE activity calmed down, and the velocity inside the rock, especially near the macro shear zone, gradually rose (Times $\mathrm{Q} \sim \mathrm{S}$ ).
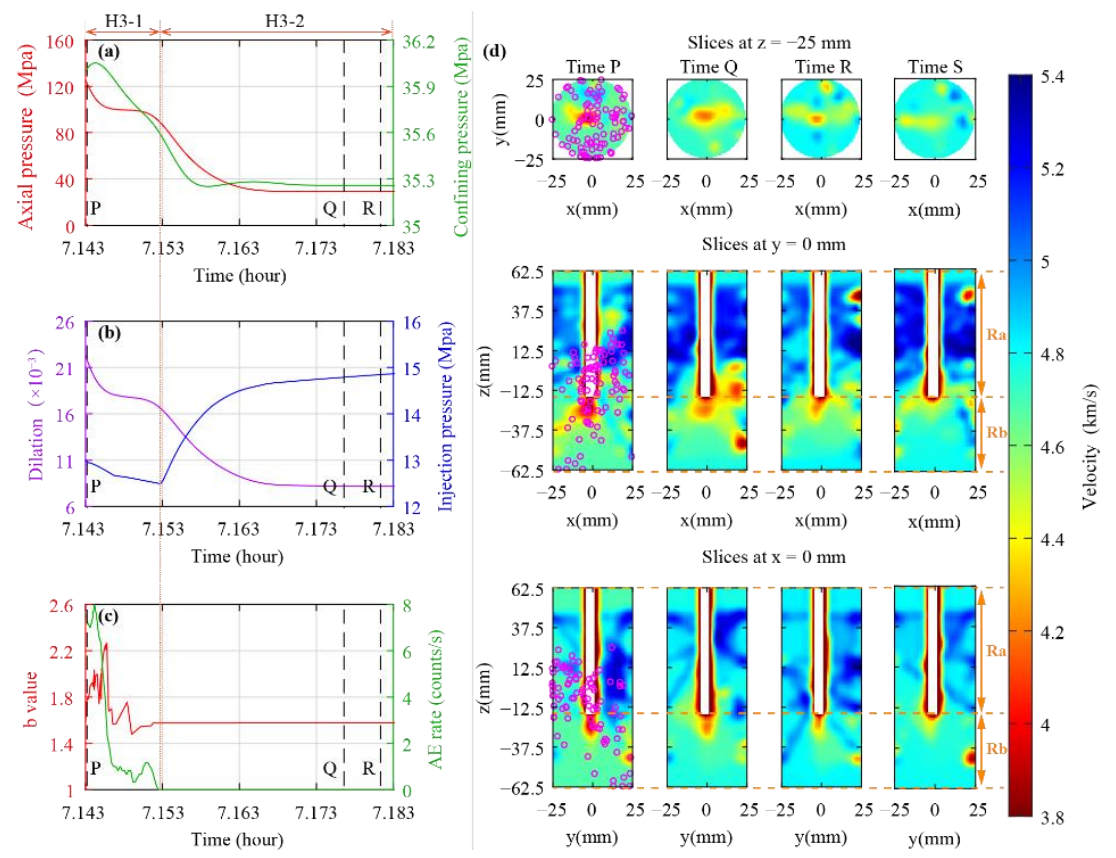

Figure 14. Mechanical response and velocity images of rocks in H3 phase: (a) axial (red line) and confining pressure (green line); (b) dilation (purple line) and water injection pressure (blue line); (c) bvalue (red line) and $\mathrm{AE}$ rate (green line); (d) slices of the $3 \mathrm{D}$ ultrasonic velocity images at different times (Times $\mathrm{P} \sim \mathrm{R}$ correspond to the times marked by black dotted lines in the left subfigures, and Time $\mathrm{S}$ corresponds to $5 \mathrm{~min}$ past Time R). The orange dotted line in the subfigures (d) represents the boundary between region $\mathrm{Ra}$ and $\mathrm{Rb}$.

\section{Discussion}

According to the above experimental results, we found some phenomena worthy of discussion during water injecting into tight sandstone. First of all, under high differential stress, a local fracture occurred at the bottom of the borehole at the initial $\mathrm{H} 0$ phase. However, no significant $\mathrm{CT}$ abnormality was observed below the borehole before the test, which indicated that these defects were unlikely to have been generated naturally. Earlier drops in $P_{\mathrm{a}}, P_{\mathrm{c}}$, and $\Delta$ than $P_{\mathrm{in}}$ demonstrated that this local fracture was not caused by the water injection. Therefore, it can be considered that these defects or microcracks were caused by uneven stress distribution at the bottom of the borehole. Although the fracture was small in scale and did not cause obvious acoustic emission activity, it still increased the permeability in this area and eventually led to the flow and diffusion of the fluid. Interestingly, the entry of water reduced the rock strength and promoted the occurrence of microfractures, which, in turn, accelerated the entry of water. Hence it can be considered that there was continuous competition between micro-fracture and water flow in this region. Moreover, this competition also occurred in the fracture nucleation phase, in which the intense microcracks increased the porosity, decreased the pore pressure, and increased the effective stress. 
Secondly, a rupture occurred earlier in the Ra region than $\mathrm{Rb}$. Since the drainage condition plays an important role in fracture behaviors, the fracture mechanism in these two regions should be carefully considered. Consistent with [62], our results also verified that the nucleation dimension and duration could be enlarged by good drainage conditions. In addition, the earlier fracture in Ra proved that the rupture could be premature in good drainage conditions. In our test, the high differential stress caused the sample to dilate before water injection. Hence, the competition between the microcrack and fluid flow started at the beginning of the water injection. Due to the better drainage conditions in Ra than in $\mathrm{Rb}$, diffusion of the pore pressure was faster in $\mathrm{Ra}$ than in $\mathrm{Rb}$. The faster diffusion meant the faster reduction in the rock strength. Hence, an earlier rupture was observed in $\mathrm{Ra}$ than in $\mathrm{Rb}$. This finding may improve the predictability of the fracture induced by the fluid injection, which has a great significance in the risk assessment of hydraulic fracturing.

Thirdly, our test showed that both "dilation hardening" and "seismic pump" modes were observed in different parts of the tight sandstone. This can be also be explained by the difference in drainage conditions. Although the "dilation hardening" had been well-established in the region $\mathrm{Ra}$, the good drainage conditions caused it to be greatly suppressed by the dilatancy-driven flowing fluid. When fracture nucleation initiated in $\mathrm{Rb}$, the water stored in the pore space of Ra was pumped into the newly generated fracture at $\mathrm{Rb}$, which promoted the rupture process in $\mathrm{Rb}$. These findings suggest that the local hydraulic condition dominated the fracture evolution. Hence, underground hydraulic conditions must be considered when designing field hydraulic fracturing schemes. After rock failure, the macroscopic shear failure greatly improved the permeability of the tight sandstone, which led to the rapid movement of water into the damaged area in the sample.

Fourthly, the evolution of the b-value was quite different from the previous understanding: the b-value decreased when the acoustic emission rates reached their peak due to the release of stress, and then gradually returned to the levels before the fracture. In this experiment, the b-value rose rapidly to its peak after the AE rate peaked. We infer that it was determined by the water injection mode. As the high-pressure fluid was injected from the borehole, the fracture before Time $\mathrm{M}$ mainly occurred in Ra, and the change in b-value is consistent with previous understanding (such as [51,63]). When the fracture propagated to the $\mathrm{Rb}$ region, the stress accumulated in this area was released. Thus, the b-value quickly reached its peak. Moreover, after rock failure, the high-pressure fluid entered the dry area quickly and led to the rapid increase in pore pressure which, in turn, caused the stress to increase and the b-value to decrease.

Finally, one may argue that the loading conditions applied to this test cannot be encountered in the field, which makes it difficult to find direct applications for this result to field conditions. In fact, our study can provide some implications for hydraulic fracturing construction in field. On one hand, our investigation proved that multiple physical means can illuminate the fracture evolution processes more comprehensively. Hence, different physical means should be used as much as possible in practice. On the other hand, the inhomogeneous distribution of fluid in the sample led to different fracture modes in different regions. This finding suggested that the fracture mechanism may be different in the reservoirs with different saturation. Additionally, the competition between solid dilatancy and fluid diffusion suggested that the real-time control of the injection pressure may be helpful to control the scale of the fracture networks.

\section{Conclusions}

In this study, the hydraulic fracturing process was analyzed and interpreted using multiple physical parameters including rock mechanics parameters, 3D ultrasonic velocity imaging results, acoustic emission activities, and X-ray CT scanning images. Although only one test was presented in our study, the combination and mutual corroboration of different physical parameters provide us with reliable conclusions. Firstly, the experimental results show that multiple physical means are beneficial for the interpretation of the rupture process. Secondly, we observed an obvious competition mechanism between stress-induced 
dilation and fluid diffusion. However, due to the low permeability of the tight sandstone, the fluid diffusion lagged behind the deformation of rock. This finding reaffirmed the importance of adjusting the water injection reasonably. Thirdly, the difference in drainage conditions also directly led to the difference in fracture mode of $\mathrm{Ra}$ and $\mathrm{Rb}$. The former was accompanied by "dilation hardening" and the "seismic pump" mode, while the latter was mainly the "seismic pump" mode. An implication of this is the possibility that the drainage conditions control the fracture mode of rock. Hence, hydraulic fracturing schemes need to be adjusted according to underground hydraulic conditions in the field.

Author Contributions: Conceptualization, W.Z. and X.C.; methodology and validation, W.Z.; formal analysis and investigation W.Z., X.C. and H.Z.; resources, X.C. and H.Z.; data curation, X.C. and H.Z.; writing—original draft preparation, W.Z.; writing—review and editing, S.W., X.C., H.Z. and H.W. All authors have read and agreed to the published version of the manuscript.

Funding: This research was funded by the General Project of the National Natural Science Foundation of China (No. 41974156), the Special Fund of the Institute of Geophysics, China Earthquake Administration (No. DQJB20K43), and the Key Project of the National Natural Science Foundation of China (No. 41930425).

Data Availability Statement: The data can be obtained from the correspondence author.

Acknowledgments: The authors thank Xinglin Lei of AIST and Ziqiu Xue of RITE for their valuable assistance in experimenting. Shiyu Li of IGP, CEA provided his beneficial comments on the paper.

Conflicts of Interest: The authors declare no conflict of interest.

\section{References}

1. Li, M.Y.; He, J.Y.; Su, Y.W. Key mechanical problems and numerical methods of hydraulic fracture in shale. Sci. Technol. Rev. 2016, 34, 32-42.

2. Liu, P.; Ju, Y.; Gao, F.; Ranjith, P.G.; Zhang, Q. CT identification and fractal characterization of 3-D propagation and distribution of hydrofracturing cracks in low-permeability heterogeneous rocks. J. Geophys. Res. Solid Earth 2018, 123, 2156-2173. [CrossRef]

3. Xie, J.; Cheng, W.; Wang, R.; Jiang, G.; Sun, D.; Sun, J. Experiments and analysis on the influence of perforation mode on hydraulic fracture geometry in the shale formation. J. Pet. Sci. Eng. 2018, 168, 133-147. [CrossRef]

4. Chong, Z.; Yao, Q.; Li, X. Experimental investigation of fracture propagation behavior induced by hydraulic fracturing in anisotropic shale cores. Energies 2019, 12, 976. [CrossRef]

5. Smirnov, V.B.; Ponomarev, A.V.; Isaeva, A.V.; Bondarenko, N.B.; Patonin, A.V.; Kaznacheev, P.A.; Stroganova, S.M.; Potanina, M.G.; Chadha, R.K.; Arora, K. Fluid initiation of fracture in dry and water saturated rocks. Izv. Phys. Solid Earth 2020, 56, 808-826. [CrossRef]

6. Falls, S.D.; Young, R.P.; Carlson, S.R.; Chow, T. Ultrasonic tomography and acoustic emission in hydraulically fractured Lac du Bonnet Grey granite. J. Geophys. Res. 1992, 97, 6867-6884. [CrossRef]

7. Jansen, D.P.; Carlson, S.R.; Young, R.P.; Hutchins, D.A. Ultrasonic imaging and acoustic emission monitoring of thermally induced microcracks in Lac du Bonnet granite. J. Geophys. Res. 1993, 98, 22231-22243. [CrossRef]

8. Grosse, C.U.; Ohtsu, M. Acoustic Emission Testing; Springer Science \& Business Media: New York, NY, USA, 2008.

9. Stoeckhert, F.; Molenda, M.; Brenne, S.; Alber, M. Fracture propagation in sandstone and slate-Laboratory experiments, acoustic emissions and fracture mechanics. J. Rock Mech. Geotech. Eng. 2015, 7, 237-249. [CrossRef]

10. Jiang, Z.; Li, Q.; Hu, Q.; Liang, Y.; Xu, Y.; Liu, L.; Wu, X.; Li, X.; Wang, X.; Hu, L.; et al. Acoustic emission characteristics in hydraulic fracturing of stratified rocks: A laboratory study. Powder Technol. 2020, 371, 267-276. [CrossRef]

11. Kiyoo, M.O.G.I. Study of Elastic Shocks Caused by the Fracture of Heterogeneous Materials and its Relations to Earthquake Phenomena; Bulletin of the Earthquake Research Institute, University of Tokyo: Tokyo, Japan, 1962; pp. 125-173.

12. Main, I.G.; Meredith, P.G.; Sammonds, P.R. Temporal variations in seismic event rate and b-values from stress corrosion constitutive laws. Tectonophysics 1992, 211, 233-246. [CrossRef]

13. Moura, A.; Lei, X.; Nishisawa, O. Self-similarity in rock cracking and related complex critical exponents. J. Mech. Phys. Solids 2006, 54, 2544-2553. [CrossRef]

14. Meredith, P.; Main, I.G.; Jones, C. Temporal variations in seismicity during quasi-static and dynamic rock failure. Tectonophysics 1990, 175, 249-268. [CrossRef]

15. Lei, X. Typical phases of pre-failure damage in granitic rocks under differential compression. Geol. Soc. London Spéc. Publ. 2006, 261, 11-29. [CrossRef]

16. Lockner, D.A.; Byerlee, J.D.; Kuksenko, V.; Ponomarev, A.; Sidorin, A. Quasi-static fault growth and shear fracture energy in granite. Nature 1991, 350, 39-42. [CrossRef] 
17. Aker, E.; Kühn, D.; Vavrycuk, V.; Soldal, M.; Oye, V. Experimental investigation of acoustic emissions and their moment tensors in rock during failure. Int. J. Rock Mech. Min. Sci. 2014, 70, 286-295. [CrossRef]

18. Chang, S.-H.; Lee, C.-I. Estimation of cracking and damage mechanisms in rock under triaxial compression by moment tensor analysis of acoustic emission. Int. J. Rock Mech. Min. Sci. 2004, 41, 1069-1086. [CrossRef]

19. Lei, X.; Nishizawa, O.; Kusunose, K.; Satoh, T. Fractal Structure of the Hypocenter Distributions and Focal Mechanism Solutions of Acoustic Emission in Two Granites of Different Grain Sizes. J. Phys. Earth 1992, 40, 617-634. [CrossRef]

20. Ohtsu, M. Simplified moment tensor analysis and unified decomposition of acoustic emission source: Application to in situ hydrofracturing test. J. Geophys. Res. Solid Earth 1991, 96, 6211-6221. [CrossRef]

21. Zhai, H.; Chang, X.; Wang, Y.; Lei, X.; Xue, Z. Analysis of acoustic emission events induced during stress unloading of a hydraulic fractured Longmaxi shale sample. J. Pet. Sci. Eng. 2020, 189, 106990. [CrossRef]

22. Lockner, D.; Byerlee, J.D. Hydrofracture in Weber Sandstone at high confining pressure and differential stress. J. Geophys. Res. Space Phys. 1977, 82, 2018-2026. [CrossRef]

23. Zoback, M.D.; Rummel, F.; Jung, R.; Raleigh, C.B. Laboratory hydraulic fracturing experiments in intact and pre-fractured rock. Int. J. Rock Mech. Min. Sci. Geomech. Abstr. 1977, 14, 49-58.

24. Liu, J.Z.; Gao, L.S.; Zhang, X. Observations on the acoustic emission in an in-house hydrofracturing simulation experiment. Acta Pet. Sin. 1990, 11, 73-78.

25. Chitrala, Y.; Sondergeld, C.H.; Rai, C.R. Acoustic emission studies of hydraulic fracture evolution using different fluid viscosities. In Proceedings of the 46th US Rock Mechanics/Geomechanics Symposium held in Chicago, Chicago, IL, USA, $24-27$ June 2012.

26. Chen, L.-H.; Chen, W.-C.; Chen, Y.-C.; Benyamin, L.; Li, A.-J. Investigation of Hydraulic Fracture Propagation Using a Post-Peak Control System Coupled with Acoustic Emission. Rock Mech. Rock Eng. 2014, 48, 1233-1248. [CrossRef]

27. Stanchits, S.; Surdi, A.; Gathogo, P.; Edelman, E.; Suarez-Rivera, R. Onset of Hydraulic Fracture Initiation Monitored by Acoustic Emission and Volumetric Deformation Measurements. Rock Mech. Rock Eng. 2014, 47, 1521-1532. [CrossRef]

28. Stanchits, S.; Burghardt, J.; Surdi, A. Hydraulic Fracturing of Heterogeneous Rock Monitored by Acoustic Emission. Rock Mech. Rock Eng. 2015, 48, 2513-2527. [CrossRef]

29. Hampton, J.; Matzar, L.; Gutierrez, M. AE investigation of multi-wellbore hydraulic fractures at the laboratory scale. In Proceedings of the 50th US Rock Mechanics/Geomechanics Symposium, Houston, TX, USA, 26-29 June 2016.

30. King, M.S. Wave velocities in overburden in rocks as a function of changes pressure and pore fluid saturants. Geophysics 1966, 31, 50-73. [CrossRef]

31. Toksöz, M.N.; Johnston, D.H.; Timur, A. Attenuation of seismic waves in dry and saturated rocks: I. Laboratory measurements. Geophysics 1979, 44, 681-690. [CrossRef]

32. Johnston, D.H.; Toksöz, M.N.; Timur, A. Attenuation of seismic waves in dry and saturated rocks: II. Mechanisms. Geophysics 1979, 44, 691-711. [CrossRef]

33. Shi, G.; Shen, W.L.; Yang, D.Q. The relationship of wave velocities with saturation and fluid distribution in pore space. Chin. J. Geophys. 2003, 46, 138-142. [CrossRef]

34. Deng, J.X.; Wang, S.X.; Yu, J. The effects of pore fluid distribution to the experimental velocity of partially saturated reservoir sandstones. Geophys. Prospect. Pet. 2005, 44, 495-500.

35. Monsen, K.; Johnstad, S. Improved understanding of velocity-saturation relationships using 4D computer-tomography acoustic measurements. Geophys. Prospect. 2005, 53, 173-181. [CrossRef]

36. Yanagidani, T.; Terada, M. Water infiltration in rock observed by CT using P and S waves. Doboku Gakkai Ronbunshu 1987, 1987, 83-89. [CrossRef]

37. Scott, T.E.; Ma, Q.; Roegiers, J.C.; Reches, Z. Dynamic Stress Mapping Utilizing Ultrasonic Tomography. In Proceedings of the 1st North American Rock Mechanics Symposium, Austin, TX, USA, 1-3 June 1994.

38. Martins, J.L.; A Soares, J.; Da Silva, J.C. Ultrasonic travel-time tomography in core plugs. J. Geophys. Eng. 2007, 4, 117-127. [CrossRef]

39. Mitra, R.; Westman, E.C. Investigation of the stress imaging in rock samples using numerical modeling and laboratory tomography. Int. J. Geotech. Eng. 2009, 3, 517-525. [CrossRef]

40. Brantut, N. Time-resolved tomography using acoustic emissions in the laboratory, and application to sandstone compaction. Geophys. J. Int. 2018, 213, 2177-2192. [CrossRef]

41. He, T.M.; Zhao, Q.; Ha, J.; Xia, K.; Grasselli, G. Understanding progressive rock failure and associated seismicity using ultrasonic tomography and numerical simulation. Tunn. Undergr. Space Technol. 2018, 81, 26-34. [CrossRef]

42. Masuda, K.; Nishizawa, O.; Kusunose, K.; Satoh, T.; Takahashi, M.; Kranz, R.L. Positive feedback fracture process induced by nonuniform high-pressure water flow in dilatant granite. J. Geophys. Res. Space Phys. 1990, 95, 21583-21592. [CrossRef]

43. Lei, X.; Funatsu, T.; Ma, S.; Liu, L. A laboratory acoustic emission experiment and numerical simulation of rock fracture driven by a high-pressure fluid source. J. Rock Mech. Geotech. Eng. 2016, 8, 27-34. [CrossRef]

44. Zhu, W.; Chang, X.; Zhai, H.; Wang, S. Three-dimensional ultrasonic imaging and acoustic emission monitoring of hydraulic fracture in tight sandstones. In Proceedings of the 82nd EAGE Conference \& Exhibition 2020, Amsterdam, The Netherlands, 18-21 October 2020.

45. Krilov, Z.; Goricnik, B. A study of hydraulic fracture orientation by X-ray computed tomography (CT). In Proceedings of the SPE European Petroleum Conference, Milan, Italy, 22-24 October 1996; pp. 69-74. 
46. Hampton, J.C.; Hu, D.; Matzar, L.; Gutierrez, M. Cumulative volumetric deformation of a hydraulic fracture using acoustic emission and micro-CT imaging. In Proceedings of the 48th US Rock Mechanics/Geomechanics Symposium, Minneapolis, MN, USA, 1-4 June 2014.

47. Liu, N.-Z.; Zou, Y.-S.; Ma, X.-F.; Li, N.; Wu, S. Study of hydraulic fracture growth behavior in heterogeneous tight sandstone formations using CT scanning and acoustic emission monitoring. Pet. Sci. 2018, 16, 396-408. [CrossRef]

48. Jiang, C.; Niu, B.; Yin, G.; Zhang, D.; Yu, T.; Wang, P. CT-based 3D reconstruction of the geometry and propagation of hydraulic fracturing in shale. J. Pet. Sci. Eng. 2019, 179, 899-911. [CrossRef]

49. Zhu, W. Research on the active and passive ultrasonic imaging. In Institute of Geology and Geophysics, Chinese Academy of Sciences; University of Chinese Academy of Sciences: Beijing, China, 2019.

50. Xue, Q.; Wang, Y.; Zhai, H.; Chang, X. Automatic Identification of Fractures Using a Density-Based Clustering Algorithm with Time-Spatial Constraints. Energies 2018, 11, 563. [CrossRef]

51. Li, X.; Lei, X.; Li, Q. Fault nucleation of tight sandstone by investigation of mechanical, acoustic, and hydraulic responses. Eng. Geol. 2021, 292, 106254. [CrossRef]

52. Bobrova, M.; Stanchits, S.; Shevtsova, A.; Filev, E.; Stukachev, V.; Shayahmetov, T. Laboratory Investigation of Hydraulic Fracture Behavior of Unconventional Reservoir Rocks. Geosciences 2021, 11, 292. [CrossRef]

53. Stanchits, S.; Mayr, S.; Shapiro, S.; Dresen, G. Fracturing of porous rock induced by fluid injection. Tectonophysics 2011, 503, 129-145. [CrossRef]

54. Vogel, C.R. Computational Methods for Inverse Problems; Society for Industrial and Applied Mathematics: Philadelphia, PA, USA, 2002.

55. Hansen, P.C. Discrete Inverse Problems Insight and Algorithms; Society for Industrial and Applied Mathematics: Philadelphia, PA, USA, 2010

56. Tikhonov, A.N.; Arsenin, V.Y. Solutions of Ill-Posed Problems; V. H. Winston \& Sons: Washington, DC, USA; John Wiley \& Sons: New York, NY, USA, 1977.

57. Zhu, W.; Chang, X.; Wang, Y.; Zhai, H.; Yao, Z. Reconstruction of hydraulic fractures using passive ultrasonic travel-time tomography. Energies 2018, 11, 1321. [CrossRef]

58. Kurz, J.H.; Grosse, C.U.; Reinhardt, H.W. Strategies for reliable automatic onset time picking of acoustic emissions and of ultrasound signals in concrete. Ultrasonics 2005, 43, 538-546. [CrossRef]

59. Lei, X. Evolution of b-Value and Fractal Dimension of Acoustic Emission Events During Shear Rupture of an Immature Fault in Granite. Appl. Sci. 2019, 9, 2498. [CrossRef]

60. Hassouna, M.S.; Farag, A.A. MultiStencils Fast Marching Methods: A Highly Accurate Solution to the Eikonal Equation on Cartesian Domains. IEEE Trans. Pattern Anal. Mach. Intell. 2007, 29, 1563-1574. [CrossRef]

61. Scholz, C.H. The Mechanics of Earthquakes and Faulting, 3rd ed.; Cambridge University Press: New York, NY, USA, 2019.

62. Lei, X.; Tamagawa, T.; Tezuka, K.; Takahashi, M. Role of drainage conditions in deformation and fracture of porous rocks under triaxial compression in the laboratory. Geophys. Res. Lett. 2011, 38, L24310. [CrossRef]

63. Li, X.; Lei, X.; Li, Q. Injection-induced fracturing process in a tight sandstone under different saturation conditions. Environ. Earth Sci. 2016, 75, 1466. [CrossRef] 